\title{
Un aspecto de la reforma administrativa: la comarcalización de Aragón
}

\author{
José María Hernández de la Torre y García \\ Director del Instituto Aragonés de Administración Pública
}

Sumario: 1. INTRODUCCIÓN. 2. DISTRIBUCIÓN TERRITORIAL DE LA POBLACIÓN ARAGONESA. 3. LEGISLACIÓN. 4. NATURALEZA, FINES Y POTESTADES. 5. CREACIÓN. 6. ORGANIZACIÓN. 7. COMPETENCIAS. 8. TRANSFERENCIAS. 9. OTRAS ATRIBUCIONES. 10. COMARCAS Y MANCOMUNIDADES DE MUNICIPIOS. 11. GESTIÓN. 12. PERSONAL. 13. FINANCIACIÓN. 14. MEDIDAS COMPLEMENTARIAS. 15. CONSIDERACIÓN FINAL.

\section{INTRODUCCIÓN}

La Constitución Española no menciona expresamente las comarcas, pero contempla la posible existencia de entes territoriales de nivel intermedio entre el municipio y la provincia, al decir que se podrán crear agrupaciones de municipios diferentes de la provincia (art. 141.3) y prever que mediante la agrupación de municipios limítrofes, los Estatutos podrán establecer circunscripciones territoriales propias, que gozarán de plena personalidad jurídica (art. 152.3). Como es bien sabido, el Tribunal Constitucional ha fijado su doctrina sobre la comarca fundamentalmente en las sentencias 32/1981, de 28 de julio, y 214/89, de 21 de diciembre.

La Ley 7/1985, de 2 de abril, Reguladora de las Bases del Régimen Local reconoce la condición de Entidad local a las comarcas u otras entidades que agrupen varios municipios, instituidas por las Comunidades Autónomas de conformidad con esta Ley y los correspondientes Estatutos de Autonomía (art. 3.2.b).

El artículo 5 del Estatuto de Autonomía de Aragón reza que Aragón estructura su organización territorial en municipios y provincias, para añadir seguidamente que una ley de Cortes de Aragón podrá ordenar la constitución y regulación de las comarcas. En su artículo 35.1.2 $2^{\mathrm{a}}$ y $3^{\mathrm{a}}$, declara que corresponde a la Comunidad Autónoma la competencia exclusiva en las materias de Régimen local y de régimen estatutario de los funcionarios de la Comunidad Autónoma de Aragón y de su Administración Local, en ambos casos sin perjuicio de lo dispuesto en el número dieciocho del apartado 1 del artículo 149 de la Constitución. 


\section{DISTRIBUCIÓN TERRITORIAL DE LA POBLACIÓN ARAGONESA}

Sobre el nueve por ciento de la superficie de España que representan los casi 48.000 kilómetros cuadrados del territorio de Aragón vive tan sólo un tres por ciento de su población total, esto es, menos de un millón doscientos mil habitantes. Pero más de la mitad de ellos están concentrados en la capital de la Comunidad Autónoma, Zaragoza, mientras que el resto se dispersa en 729 municipios, con 1.545 núcleos habitados, muy desigualmente repartidos por las diversas zonas de las tres provincias aragonesas, que en su conjunto componen la segunda región más desértica $-\mathrm{y}$ desertizada - de la Península, con una densidad demográfica media inferior a las 25 personas por kilómetro cuadrado. Apenas una decena de municipios alcanzan los 10.000 vecinos, y únicamente las otras capitales provinciales - Huesca y Teruel - sobrepasan los 20.000, mientras que 338 municipios cuentan con menos de 250, y 111 de ellos no llegan al centenar de almas. $\mathrm{Si}$ a esto se une el acusado envejecimiento de la pirámide demográfica, no debe extrañar que más de la mitad de los pueblos de las áreas rurales de Aragón tengan muy sombrías perspectivas de supervivencia a medio plazo.

Tal supervivencia está, naturalmente, ligada a la posibilidad de acceso a los servicios básicos, para cuya prestación los pequeños municipios carecen de capacidad, tanto económica como técnica, infraestructural y humana. La única manera de garantizarlos - y evitar, con ello, la discriminación por razón de residencia entre los ciudadanos aragoneses- es acudir a las economías de escala que hagan viables su establecimiento, equipamiento, funcionamiento y mantenimiento, por medio de una organización supramunicipal que compense las carencias debidas al reseñado minifundismo poblacional.

Esta es la razón fundamental del proceso de comarcalización de Aragón, que, de acuerdo con la facultad que el Estatuto de Autonomía otorga a las Cortes aragonesas, pretende apoyarse en la existencia empíricamente contrastada de las comarcas, como realidades geográficas con trayectorias históricas, características culturales e intereses económicos comunes, por encima de las tradicionales rivalidades que eventualmente pueden enfrentar a localidades vecinas; pero, siempre, sobre la base del respeto a la autonomía municipal y a sus competencias, entendiendo el municipio como la unidad básica de la organización político-territorial, por su máxima proximidad al ciudadano. 
Por todo ello, la política comarcalizadora ha podido emprenderse con el consenso generalizado de las fuerzas políticas y ha sido positivamente acogida - superados algunos comprensibles recelos iniciales- por las poblaciones afectadas y por sus representantes institucionales, como una consecuencia natural del principio descentralizador que, proclamado constitucionalmente, inspira el Estatuto de Autonomía.

\section{LEGISLACIÓN}

Tras las referencias a los ámbitos territoriales comarcales como áreas de desarrollo, ordenación y gestión contenidos, sin precisar jurídicamente el concepto de comarca, en la Ley aragonesa 11/1992, de 24 de noviembre, de Ordenación del Territorio, las Cortes de Aragón, al amparo de la previsión estatutaria, aprobaron la Ley 10/1993, de 4 de noviembre, de Comarcalización de Aragón, mediante la que se institucionalizaba — dice el Preámbulo- el hecho comarcal, como nuevo nivel de Administración Pública para estructurar la organización territorial de Aragón, entendiendo que la comarca puede ser el más adecuado y activo protagonista y gestor de las directrices de política territorial.

El propio Preámbulo se apresura a garantizar que la creación de la comarca como entidad local no pretende cuestionar ningún otro nivel de la Administración Local, si bien la puesta en marcha de la nueva entidad implicará una cierta redistribución de las funciones de las otras Administraciones, posibilidad admitida por la crucial sentencia del Tribunal Constitucional de 28 de julio de 1981, en aras de una más eficaz prestación de los servicios públicos y para posibilitar la pervivencia institucional, democrática y representativa de los pequeños municipios carentes de capacidad para la gestión de las competencias administrativas generales y —más aún- para asumir la de aquéllas que hayan de ser objeto de descentralización.

La Ley se configura como la norma-marco que establece las reglas generales a las que se ajustará la organización comarcal aragonesa, y autoriza a que cada comarca, a través de su propia normativa — contenida en la respectiva ley de creación-, regule las peculiaridades específicas de sus municipios, población y territorio.

En sus disposiciones adicionales, la Ley daba a la Diputación General un plazo de seis meses para unificar todas las divisiones comarcales y supramunicipales que vinieran aplicando los distintos Departamentos de la 
Administración de la Comunidad Autónoma para la organización y gestión de los servicios a su cargo, con el fin de homogeneizar el mapa comarcal; y otro plazo, de cinco meses, para someter a consulta de todos los municipios aragoneses, de las mancomunidades intermunicipales y de las provincias una propuesta de delimitación comarcal y su capitalidad.

El resultado del proceso así iniciado fue la Ley 8/1996, de 2 de diciembre, de Delimitación Comarcal de Aragón, que define treinta y tres comarcas, con la denominación de cada una y la enumeración de los municipios que las integran. Este mapa, que sólo se modificará por ley, es el que ha de servir de base para el ejercicio de la iniciativa comarcal, que podrá usarse también para constituir comarcas mayores, que comprendan completas dos o más de las demarcaciones establecidas. La Diputación General queda obligada a impulsar la adaptación de las mancomunidades de municipios de servicios generales a los ámbitos comarcales, que son también los que los Departamentos autonómicos habrán de utilizar como base territorial para sus servicios periféricos.

La delimitación comarcal, que tiene un indudable sustrato histórico y una parcial similitud con la tradicional demarcación de los partidos judiciales, se hizo sobre todo en función de criterios de cercanía y accesibilidad de los servicios que deben prestarse. No han influido, en cambio, las proporciones demográficas: mientras la comarca de Zaragoza cuenta con más de 650.000 habitantes, los de la del Maestrazgo no llegan a 4.000. Tampoco el número de municipios afectados: la Comunidad de Calatayud está formada por 67 y la de Caspe por 6. Ni la extensión territorial: la comarca de las Cinco Villas tiene 2.876 metros cuadrados, frente a los 416 de la de la Ribera Alta del Ebro...

Cada una de las comarcas requiere, para su establecimiento y regulación, una ley de Cortes de Aragón específica, que contendrá su estatuto propio: denominación, ámbito territorial, capitalidad, composición y funcionamiento de sus órganos de gobierno, competencias, recursos económicos y peculiaridades.

La Ley 7/1998, de 16 de julio, que aprueba las Directrices de Ordenación Territorial considera el sistema de comarcalización como el soporte de la política de equipamientos comunitarios y hace diversas referencias a las comarcas, remitiéndose al proceso previsto en las leyes 10/1993 y 8/1996 respecto de la estructura comarcal y otros aspectos. Por su parte, la Ley 7/1999, de 9 de abril, de Administración Local de Aragón, incluye sistemáticamente a las comarcas entre las demás entidades locales, distintas del municipio, y les dedica un Capítulo (el II del Título III), con un único 
artículo, el 75, que, bajo la rúbrica de remisión a la Ley de Comarcalización de Aragón, se limita a declarar que, de conformidad con lo establecido en el artículo 5 del Estatuto de Autonomía de Aragón, los municipios limítrofes vinculados por características e intereses comunes podrán constituirse en comarcas, con personalidad jurídica propia y capacidad y autonomía para el cumplimento de sus fines, añadiendo en el apartado 2 que, en todo caso, la comarca deberá tener continuidad territorial, lo que determina la imposibilidad de enclaves.

Tras la aprobación de la Ley de Delimitación Comarcal se abrió un período de intensas negociaciones políticas y de concienciación popular sobre las ventajas de la comarcalización, el cual se prolongó hasta la legislatura siguiente. A partir de la Ley 9/2000, de 27 de diciembre, de creación de la Comarca del Aranda, que se convierte en pionera, se desarrolla un proceso que, desde mediados de 2001, ha experimentado una aceleración inusitada y creciente, de tal manera que, aprobadas sucesivamente por las Cortes de Aragón las demás leyes, es más que probable que antes del fin de la legislatura (en mayo de 2003) estén ya constituidas y en funcionamiento treinta y dos comarcas. Es decir, todas las previstas salvo la de Zaragoza, que, por sus singulares características demográficas y urbanas, habrá de ser objeto de una regulación diferenciada y estar sujeta a un régimen económico especial - al margen del sistema de reparto comarcal de fondos establecido, y con la asignación de compensaciones por los costes de los servicios que se le transfieran-, además de contar con la posibilidad legal de la creación del Área Metropolitana, con carácter de entidad local, a la que corresponderán, en su caso, respecto de su propio ámbito territorial, las competencias atribuidas a la comarca.

Creada y constituida la comarca, el ejercicio de sus competencias de procedencia autonómica queda supeditado la aprobación por el Gobierno de Aragón del correspondiente Decreto de traspasos, lo que puede suponer una cierta demora en la efectiva puesta en marcha de aquélla. Por eso, en la Ley 13/2000, de 27 de diciembre, de Medidas Tributarias y Administrativas — simultánea a la creación de la primera comarca-, se recoge el establecimiento de subvenciones para el sostenimiento de las comarcas durante el período que transcurra entre su creación y el efectivo traspaso de los medios humanos y materiales ligados a las transferencias y delegaciones de competencias, que serán abonadas (en cuartas partes, por trimestres anticipados) según las cuantías que se determinen para su transferencia incondicionada a las comarcas para su puesta en marcha y funcionamiento de su organización y actividades. 
Finalmente, en el proceso ha venido a incidir la Ley 23/2001, de 26 de diciembre, de Medidas de Comarcalización, medidas que tienen el carácter de complementarias de la legislación de comarcalización vigente y, al tiempo, cumplen la finalidad de constituirse en marco de referencia para las posteriores leyes de creación de comarcas. Tales medidas se refieren, sobre todo, a la determinación actualizada de las competencias que pueden asumir las comarcas (modificando la relación contenida en la Ley de 1993), pero también a cuestiones complementarias sobre organización, personal, financiación de las transferencias y algunas otras muy concretas. Con lo que pretende completarse el marco legislativo en el que se encuadra la realización de este ambicioso proyecto de vertebración territorial de Aragón.

\section{NATURALEZA, FINES Y POTESTADES}

Las comarcas gozan de la condición de entidades locales, con personalidad jurídica propia, constituidas por los municipios limítrofes vinculados por características e intereses comunes. La relativa indeterminación del aserto pretende paliarse disponiendo que el territorio de cada comarca coincida con los espacios geográficos en que se estructuren las relaciones básicas de la actividad económica y cuya población esté vinculada por características sociales, historia y tradición comunes que definan bases peculiares de convivencia. Ese territorio abarca todo el conjunto de los términos municipales que integran la comarca, de forma que cualquier alteración de dichos términos obligará a la tramitación de la correlativa modificación de la división comarcal. Por lo demás, cada municipio sólo podrá pertenecer a una comarca.

La ley de creación establece la denominación por la que será identificada la comarca, así como la capitalidad, en la que tendrán la sede oficial sus órganos, sin perjuicio de que los servicios que preste la comarca puedan fijarse en cualquier lugar dentro de los límites comarcales, lo que supondrá otorgar al municipio correspondiente el carácter de capital a los efectos de la gestión o de la representatividad externa de la materia en cuestión.

Las denominaciones han obedecido, en general, a la tradición (se ha registrado alguna alteración después: Tarazona y el Moncayo en lugar de Somontano del Moncayo, Valdejalón en vez de Jalón Medio), lo que ha llevado en determinados casos a la aplicación del bilingüismo (Hoya de Huesca/Plana de Uesca, Bajo Cinca/Baix Cinca, La Litera/Llitera, Bajo 
Aragón-Caspe/Baix Aragó-Casp, Matarraña/Matarranya). También la capitalidad estaba clara en casi todas las comarcas, aunque en algunas de ellas se ha optado por la designación de capitales compartidas, una histórica o cultural y otra administrativa: L'Aínsa y Boltaña en Sobrarbe, Graus y Benabarre en Ribagorza, Binéfar y Tamarite en La Litera, Utrillas y Montalbán en Cuencas Mineras...

Se proclama la voluntariedad del impulso comarcalizador, por cuanto la creación de comarcas no exigirá su generalización a todo el territorio de la Comunidad Autónoma. Sin embargo, la Ley atribuye a la Diputación General la facultad de iniciativa para la creación de comarcas, siempre y cuando el proceso de comarcalización se haya desarrollado en, al menos, el setenta por ciento del territorio aragonés. El principio de voluntariedad cede, por consiguiente, ante los de homogeneización y racionalización del régimen jurídico.

Las comarcas, en cuanto entidades locales territoriales, tienen capacidad y autonomía para el cumplimiento de sus fines propios. Éstos se concretan en la prestación de servicios y la gestión de actividades de ámbito supramunicipal, representando los intereses de la población y territorio comarcales, en defensa de una mayor solidaridad y equilibrio dentro de Aragón; a lo que debe añadirse la cooperación con los municipios integrantes para el cumplimiento de sus fines propios.

Para la consecución de esos fines, en el ejercicio de sus competencias, se reconocen expresamente a la comarca las potestades siguientes:

- Potestad reglamentaria

- Potestad de autoorganización

- Potestad financiera

- Potestad tributaria, circunscrita al establecimiento de tasas por prestación de servicios o realización de actividades, imposición de contribuciones especiales y fijación de precios públicos

- Potestad de programación y planificación

- Presunción de legitimidad de sus actos y ejecutividad de éstos

- Potestad de ejecución forzosa

- Potestad sancionadora

— Potestad de revisión de oficio de sus actos y acuerdos 
- Inembargabilidad de sus bienes y derechos, en los términos previstos en las leyes

- Prelaciones, preferencias y demás prerrogativas reconocidas en la Hacienda Pública en relación con sus créditos, sin perjuicios de las que correspondan a las Haciendas del Estado y de la Comunidad Autónoma

- Potestad expropiatoria

— Potestad de investigación, deslinde y recuperación de oficio de sus bienes.

\section{CREACIÓN}

Queda dicho que las comarcas se crean por Ley de Cortes de Aragón.

La iniciativa ha de basarse en un estudio documentado en el que se justifique la creación de la comarca, mediante la apelación a la existencia de los vínculos históricos, económicos, sociales y culturales que la configuran y a la eficacia administrativa de los servicios que se vayan a prestar, proponiendo, además, su denominación, los municipios que comprende, la capitalidad, la relación de funciones y servicios a desempeñar, la composición de sus órganos de gobierno, los medios económicos y el presupuesto estimativo de puesta en marcha y coste ordinario de funcionamiento.

La facultad de iniciativa se atribuye, en primer lugar a los municipios: todos los que hayan de integrar la comarca, o bien algunos de ellos, en número no inferior a las dos terceras partes del total de los afectados y que, además, representen dos tercios del censo electoral del territorio. Los acuerdos habrán de ser adoptados por mayoría absoluta en el pleno de cada uno de los ayuntamientos o concejos abiertos de los municipios promotores de la iniciativa. Una vez que reciba el testimonio de esos acuerdos y la documentación justificativa, el Departamento de Presidencia y Relaciones Institucionales del Gobierno de Aragón lo trasladará a los demás municipios comprendidos en la delimitación comarcal propuesta, con el fin de que en el plazo de tres meses adopten acuerdo sobre la iniciativa, entendiéndose si no lo hacen que no presentan objeción a ésta.

También puede ejercer la iniciativa una mancomunidad que haya obtenido la declaración de interés comarcal, mediante acuerdo de su órgano plenario de gobierno, adoptado por los dos tercios del número legal de sus miembros y que representen, al menos, a las dos terceras partes del censo 
electoral. De esta iniciativa se dará traslado a todos los municipios incluidos en el ámbito territorial de la comarca propuesta, y no podrá continuarse el trámite si se oponen expresamente las dos quintas partes de aquéllos, siempre que representen, al menos, la mitad del censo electoral del territorio; en cuyo caso no podrá reiterarse la iniciativa hasta la celebración de nuevas elecciones locales, o cuando los municipios que se opusieron reconsideren su negativa y acuerden sumarse a la iniciativa.

Lo mismo ocurre si la iniciativa es de la Diputación General, que, como arriba se dijo, podría adoptar el correspondiente acuerdo cuando el proceso de comarcalización estuviese desarrollado al menos en el setenta por ciento del territorio de la Comunidad Autónoma.

Por otro lado, la Ley de Administración Local de Aragón prevé (art. 76) que puede crearse la entidad metropolitana de Zaragoza, integrada por los municipios comprendidos en el territorio correspondiente, mediante ley que determinará su delimitación territorial, sus órganos de gobierno y administración y sus competencias, y cuyo anteproyecto será sometido a informe de los ayuntamientos afectados.

\section{ORGANIZACIÓN}

El gobierno y la administración de la comarca corresponden al Consejo Comarcal, que está integrado por el Presidente y los Consejeros. Éstos, junto con los Vicepresidentes, son los órganos necesarios, que han de existir en todas las comarcas; a los que debe añadirse una Comisión especial de Cuentas, constituida por miembros de los grupos políticos integrantes del Consejo Comarcal, con la función de informar las cuentas anuales de la entidad antes de su aprobación.

En las comarcas que así lo tengan previsto en su estatuto, o en el reglamento orgánico que aprueben, podrá existir también una Comisión de Gobierno, para la asistencia al Presidente y el cumplimiento de las funciones que éste o el Consejo le deleguen, o el reglamente le atribuya, integrada por el propio Presidente y un número de Consejeros no superior a un tercio de su número legal, nombrados y separados libremente por aquél, pero con inclusión obligada, entre ellos, de los Vicepresidentes.

El reglamento orgánico comarcal, que ha de ser aprobado por el Consejo Comarcal con el voto favorable de la mayoría absoluta, podrá regular los órganos complementarios que considere necesarios, la estructura admi- 
nistrativa del ente comarcal y las relaciones entre los órganos comarcales y los municipios integrantes de la comarca.

Por su parte, el Consejo Comarcal está integrado por el número de miembros que resulte de la aplicación de una escala en función de la población residente en cada comarca: 19 hasta los 10.000 habitantes, 25 hasta $25.000,35$ hasta 50.000 y 39 para las de cifra superior. Para su elección, la Junta Electoral de Zona —o la Junta Electoral de Aragón cuando el mandato de aquélla esté concluido-, una vez constituidos todos los ayuntamientos de la comarca, formará una relación, por orden decreciente, de los partidos, coaliciones, federaciones y agrupaciones de electores que hayan obtenido algún concejal y, al menos, el tres por ciento de los votos de la comarca, y distribuirá los puestos dividiendo el número de votos obtenido por cada candidatura por uno, dos, tres o más, hasta un número de puestos igual a los correspondientes al Consejo Comarcal, atribuyéndose éstos a las listas que obtengan los cocientes mayores, por orden decreciente; si se produjeran coincidencias de cocientes, la vacante se atribuirá a la lista con mayor número de votos, y si persistiese el empate, se resolverá por sorteo.

Rigen las causas de inelegibilidad establecidas por la Ley Orgánica del Régimen Electoral General y, en su caso, por la Ley Electoral de Aragón, así como los motivos de incompatibilidad previstos para los Diputados provinciales. En todo caso, la pérdida de la condición de concejal determinará también la pérdida de la condición de miembro del Consejo Comarcal.

La duración del mandato de los miembros del Consejo comarcal coincidirá con la de las Corporaciones a las que representen. Una vez finalizado, continuarán aquéllos en funciones únicamente para la administración ordinaria, hasta la toma de posesión de sus sucesores, sin que en ningún caso, mientras permanezca tal circunstancia, puedan adoptar acuerdos para los cuales sea legalmente necesaria una mayoría cualificada.

El primer día hábil después de transcurridos quince naturales, contados desde el siguiente a la proclamación de los miembros electos, el Consejo Comarcal se constituirá en sesión pública, en la capital de la comarca, presidido por una mesa de edad, y en esa misma sesión elegirá, de entre sus miembros, a su Presidente.

Para serlo, el candidato habrá de obtener la mayoría absoluta en la primera votación, o la mayoría simple en la segunda. En caso de empate, se procederá a una tercera votación y, si en ella se produce otra vez empate, 
será elegido el candidato de la lista con más consejeros. Si las listas tienen el mismo número de consejeros, se elegirá al de la que cuente con un mayor número de concejales en la comarca. Si de este criterio resulta nuevo empate, el elegido será el de la lista que mayor número de votos hubiera obtenido dentro de la comarca en las últimas elecciones municipales. De persistir aún el empate, se decidirá mediante sorteo.

El Presidente puede ser destituido mediante moción de censura, según el procedimiento regulado para los municipios en la Ley Orgánica del Régimen Electoral General, a cuyo efecto todos los Consejeros podrán ser candidatos al cargo.

Los Vicepresidentes (en número de hasta cuatro) son nombrados y cesados libremente por el Presidente de entre los Consejeros comarcales, y le sustituyen, por su orden (el que se derive del nombramiento, debe entenderse), en los casos de vacante, ausencia o enfermedad, además de ejercer aquellas atribuciones que expresamente les delegue el Presidente.

Se aplicarán al Consejo Comarcal y a su Presidente las normas de la legislación de régimen local relativas al Pleno del Ayuntamiento y al Alcalde, en cuanto al ejercicio de las respectivas atribuciones y al funcionamiento de los órganos de gobierno.

El Consejo Comarcal deberá celebrar como mínimo una sesión ordinaria cada tres meses, sin perjuicio de que las normas particulares de cada comarca determinen una frecuencia mayor. También se reunirá el Consejo con carácter extraordinario, cuando sea convocado por su Presidente, bien por propia iniciativa, o bien a propuesta de la cuarta parte de sus miembros, con petición de que se incluyan asuntos determinados en el orden del día; en este caso, la celebración de la sesión extraordinaria no podrá demorarse por más de quince días hábiles desde que haya sido solicitada su convocatoria.

Las sesiones podrán celebrarse en cualquier municipio de la comarca que decida expresamente el Consejo Comarcal, de acuerdo con su reglamento orgánico.

Todo lo referente a la convocatoria, el desarrollo de las sesiones, la adopción de acuerdos, el quórum de constitución y las votaciones se ajustará a lo dispuesto en la legislación de régimen local.

La Ley de Comarcalización prevé fórmulas de consulta a los ayuntamientos y de participación ciudadana. Respecto a la primera, establece que el reglamento orgánico comarcal regule la convocatoria a los alcaldes de 
los municipios de la comarca —o concejales en quienes ellos deleguenpara que tengan la oportunidad de informar ante el Consejo Comarcal, con carácter previo, sobre los asuntos de especial interés para el correspondiente municipio que vayan a ser sometidos a la aprobación de aquél.

Y también deberá recoger el reglamento orgánico comarcal los instrumentos y procedimientos que para la participación ciudadana están incluidos en la legislación sobre régimen local. En tal sentido, hay que recordar que la Ley 9/1999, de 9 de abril, de Administración Local de Aragón, ordena, en su artículo 155, que las Corporaciones locales facilitarán la participación ciudadana a través de los distintos medios a su alcance y, en especial, en las formas siguientes: a) remisión a los medios de comunicación social de la localidad de las convocatorias y órdenes del día de las sesiones; b) difusión adecuada y suficiente de las exposiciones públicas de actuaciones y proyectos de interés y repercusión social, y c) oficinas de información al ciudadano e implantación de medios tecnológicos que la faciliten. A lo que deben añadirse las relaciones con las asociaciones de vecinos (artículo 156) y le regulación de las consultas populares (artículo 157), todo ello en sintonía con lo establecido en los artículos 69 y siguientes de la Ley Reguladora de las Bases del Régimen Local.

\section{COMPETENCIAS}

Si bien la creación de las comarcas obedece, por una parte, a un criterio agrupador de municipios, que tiene por finalidad garantizar la prestación de determinados servicios públicos para los que muchos de los municipios integrantes carecen de capacidad suficiente, por otra se lleva a efecto con arreglo al principio de descentralización de funciones, ya que el grueso de las que va ejercer la comarca proceden de las propias de la Comunidad Autónoma, mientras que las municipales son básicamente respetadas. Este respeto queda bien recalcado cuando se dispone que la atribución de competencias a las comarcas, y su ejercicio por parte de éstas, se entiende sin perjuicio de las estatales y de las autonómicas y, en particular, de las competencias de los municipios que resultan de su autonomía municipal garantizada constitucionalmente y reflejada en las prescripciones especificas de la legislación sectorial aplicable. Por lo tanto, el proceso se inspira en el espíritu descentralizador que informa la configuración constitucional del Estado de las Autonomías, como un paso más tras la consolidación de las Comunidades Autónomas, que, en el caso de Aragón, consiste en trasladar aquel espíritu a su propio territorio. 
La legislación aragonesa sobre comarcas adopta, para la distribución competencial, un método en cierto modo similar, salvando las distancias, al utilizado para la asignación de competencias estatales a las Comunidades Autónomas: se fija el catálogo de competencias propias de las comarcas, que son las que podrán recogerse explícitamente en cada una de las leyes de creación y ser ejercidas por los nuevos entes a partir del momento en que la Administración autonómica les traspase las funciones y servicios correspondientes.

No existe, sin embargo, la segunda lista, esto es, la de las materias de competencia exclusiva de la Comunidad Autónoma. De ello surgía una cierta imprecisión en la Ley de Comarcalización de 1993, cuando decía que la Comunidad Autónoma podrá transferir o delegar a las comarcas la titularidad o el ejercicio de competencias, ya que no resulta fácilmente comprensible la figura de la delegación referida a competencias que se proclaman propias del ente receptor. La Ley de Medidas de 2001 solventa la cuestión dando por supuesto que es la transferencia la técnica correcta para el traspaso de los medios necesarios para el ejercicio de tales competencias. Ello comporta que la atribución de las competencias se lleva a cabo por medio de norma legal — al ser recogidas en la respectiva ley de creación-, por lo que sólo podrían ser suprimidas, en su caso, por disposición del mismo rango, y no por mera voluntad del Ejecutivo - como para la delegación-, además de no quedar sometidas en su ejercicio a los controles que sobre materias delegadas puede disponer el ente delegante.

Así que la atribución de competencias autonómicas a las comarcas se hace a título de transferencia, y se entienden —claro está- referidas al territorio de la comarca y a sus intereses propios, además de justificarse cuando se favorezca la mejor prestación de los servicios correspondientes.

El listado de competencias propias de las comarcas — que, por lo tanto, pueden ser asumidas por éstas mediante su mención expresa en la respectiva ley de creación - que figura la Ley de 1993 ha sido aumentado y parcialmente modificado por la de 2001: en el intervalo se ha producido incorporación de importantes materias de competencia estatal a la Comunidad Autónoma, y que han entrado a formar parte del paquete de lo transferible. Una vez actualizada la relación de las materias propias - que pueden ser ejercidas por las comarcas en sus respectivos territorios, de la forma y con el alcance luego precisados-, el Gobierno de Aragón, en la práctica del proceso de negociación de los traspasos, las agrupa en tres bloques para adecuar los tiempos y ritmos con que las competencias puedan ser asumidas por las comarcas: 
Primer bloque:

- acción social

- cultura

— patrimonio cultural y tradiciones populares

- deporte

- juventud

— promoción del turismo

— servicios de recogida y tratamiento de resíduos urbanos

— protección civil y prevención y extinción de incendios

Segundo bloque:

- transportes

— protección del medio ambiente

- artesanía

— protección de los consumidores y usuarios

— ferias y mercados comarcales

Tercer bloque:

- ordenación del territorio y urbanismo

— sanidad y salubridad pública

- agricultura, ganadería y montes

- energía, promoción y gestión industrial

- enseñanza

- aquellas otras que, con posterioridad a la ley, pudieran ser ejercidas por las comarcas, conforme a la legislación sectorial correspondiente.

La Ley de Medidas de Comarcalización pormenoriza después, con gran detalle, los aspectos de cada una de esas materias competenciales genéricamente mencionadas que son los que configurarán el contenido real de la competencia propia de la comarca y serán, por lo tanto, objeto de la transferencia.

Además, la comarca puede ejercer la iniciativa pública para la realización actividades económicas de interés comarcal, así como participar en la elaboración de los programas de ordenación y promoción de recursos 
agrarios y en la gestión de obras de infraestructura y de servicios públicos básicos que se incluyan en tales programas.

\section{TRANSFERENCIAS}

Para la determinación de las funciones y servicios vinculados a las competencias que hayan de ser transferidos, debe constituirse - en el plazo de un mes desde la constitución de la comarca- una Comisión Mixta de Transferencias, formada por representantes de la Comunidad Autónoma y de la comarca correspondiente, en cuyo seno debe decidirse de común acuerdo las competencias que asumirá la comarca, su financiación, los medios personales y materiales a traspasar y el calendario de los traspasos. Integrarán cada Comisión el Consejero de Presidencia y Relaciones Institucionales en calidad de Presidente, el Presidente de la Comarca como Vicepresidente, tres vocales designados por el Gobierno de Aragón y otros tres por el Consejo Comarcal, además de un Secretario - funcionario de la Administración autonómica-y, como Vicesecretario, quien ejerza la secretaría del Consejo Comarcal. Se especifican algunas reglas de funcionamiento y para lo no previsto en ellas se prevé la aplicación del régimen jurídico de los órganos colegiados.

Logrado el acuerdo en la Comisión Mixta, como culminación de las necesarias negociaciones — para las que aquélla podrá recabar los documentos e informes necesarios de ambas Administraciones-, se elevará en forma de propuesta al Gobierno de Aragón, para su aprobación mediante decreto. Éste deberá contener, en todo caso, las siguientes determinaciones:

- referencia a las funciones que pasan a la comarca correspondiente;

- referencia a las normas constitucionales, del Estatuto de Autonomía, de la legislación de comarcalización y de la legislación sectorial aplicable que justifiquen la transferencia;

- fecha efectiva del traspaso de las funciones;

- designación de los órganos que, en su caso, se traspasen;

- relaciones nominales del personal que, en su caso, se transfiera, con expresión de su número de registro de personal y, además, en el caso de los funcionarios, de su puesto de trabajo, situación administrativa y régimen de retribuciones; en el caso del personal contratado, de su categoría, puesto de trabajo y régimen de retribuciones; 
- valoración del coste de los servicios transferidos y de las tasas y precios públicos afectos, así como de las modificaciones que, en su caso, deben operarse en los Presupuestos Generales de la Comunidad Autónoma. En el caso de que existan actuaciones relativas a esos servicios y que estén dotadas con fondos procedentes de otra Administración Pública o de la Unión Europea, se hará constar expresamente, con referencia al porcentaje o cifra total de la cofinanciación;

- inventario detallado de los bienes, derechos y obligaciones de la Administración de la Comunidad Autónoma de Aragón que se transfieren;

- inventario de la documentación administrativa relativa a la transferencia de las funciones y servicios correspondientes;

- determinación de las concesiones y los contratos administrativos afectados por la transferencia, produciéndose la subrogación en los derechos y deberes de la Administración de la Comunidad Autónoma de Aragón por la comarca correspondiente;

- relación pormenorizada de los procedimientos administrativos asociados a cada función transferida, con indicación expresa de la normativa reguladora de cada procedimiento.

Los decretos de transferencia de funciones y servicios suelen dictarse para cada comarca, pero también podrían referirse al conjunto de competencias de varias comarcas. El Gobierno podrá fijar plazos para la negociación y entrega de las funciones y servicios relativos a las competencias asumibles, según los ritmos de creación de las Administraciones comarcales y de las circunstancias que, en atención a los intereses generales, puedan hacer aconsejables fases distintas para determinadas competencias; de las decisiones que a este respecto se adopten deberá darse cumplida información a las Cortes de Aragón.

\section{OTRAS ATRIBUCIONES}

Además de todo el conjunto de competencias que, procedentes de la Comunidad Autónoma, forman el grueso de las propias de la comarca, ésta puede ejercer también otras, de procedencia autonómica, provincial o municipal.

En primer lugar, la comarca podrá realizar funciones ejecutivas correspondientes a otras competencias de la Administración de la Comunidad 
Autónoma, mediante la encomienda de gestión ordinaria de determinados servicios, cuando por sus características no requieran unidad de gestión ni su ejercicio directo, para lo que será preciso que, previa conformidad del Consejo Comarcal interesado, la Diputación General adopte el acuerdo de asignación, determinando las facultades que se reserve y los medios con que dota las que encomienda.

Por su parte, las provincias podrán transferir o delegar a las comarcas (hay que entender las comprendidas en los límites territoriales respectivos) la titularidad o el ejercicio de competencias en relación con la gestión del Plan Provincial de Obras y Servicios en el ámbito comarcal y con la asistencia y cooperación técnica, jurídica y económica a los municipios.

El Gobierno de Aragón impulsará aquellas transferencias de competencias propias de las diputaciones provinciales cuya gestión por las comarcas estime apropiada — mediante comisiones mixtas creadas al efectoy en particular las correspondientes a la ejecución del Plan de Obras y Servicios en cuanto afecte al ámbito territorial de la comarca interesada, para lo que habrá ésta de disponer de la adecuada dotación económica.

Cada comarca, por su parte, podrá crear un servicio de cooperación y asistencia para prestar asesoramiento —en materias jurídico-administrativa, económica, financiera y de obras y servicios- a los municipios que lo soliciten, y ello sin perjuicio de las competencias provinciales, que, como hemos visto, pueden ser también objeto de transferencia o delegación a las comarcas. En tal caso de concurrencia de competencias, éstas deberán ejercitarse en colaboración, mediante la suscripción de un convenio entre la Diputación Provincial y el ente comarcal.

También los municipios que integran la comarca pueden delegar en ésta sus propias competencias, en cuanto se refieran a actuaciones de interés comarcal o supramunicipal y también cuando su ejercicio resulte difícil para el municipio y razones de economía y eficacia así lo aconsejen; esto es, en aquellos supuestos en que los municipios se vean incapacitados de prestar un determinado servicio, y en el marco de la dispensa de cumplimiento que, en su caso, pueda otorgar la Administración de la Comunidad Autónoma a petición del municipio interesado. Un supuesto concreto es el de la carencia de medios para sostener el puesto de Secretaría-Intervención, en que, si el municipio es dispensado, y la provincia no garantiza adecuadamente el ejercicio de la función, puede encomendarse la prestación de ésta a la comarca; la sede administrativa estable del puesto de trabajo radicará entonces en las oficinas comarcales, pero debe asegurarse la comunicación entre éstas y el municipio en cuestión, así como la asisten- 
cia del personal habilitado a las sesiones municipales y demás actos que lo requieran por su importancia o por la necesidad de asesoramiento jurídico y técnico. En cualquier caso, las comarcas podrán establecer convenios con los municipios de su ámbito para la cooperación en cualquier materia de interés común.

La transferencia o delegación de competencias exige, en cada caso, no sólo la aceptación expresa por el Consejo Comarcal —excepto cuando venga determinada por ley-, sino el traspaso de los medios precisos para su ejercicio. El problema práctico se presentará, sin duda, en el momento de determinar tales medios, no ya en cuanto a la valoración del coste, sino por lo que se refiere a su identificación, y muy especialmente en el caso de los medios personales; la norma se ha preocupado de arbitrar algunas fórmulas para la solución de tal problema, como más adelante veremos.

Junto a todo lo anterior, las comarcas tendrán a su cargo —en virtud de convenio, delegación o transferencia, según los casos- la gestión de las actuaciones prioritarias específicas que se fijen en los planes y programas territoriales aprobados en desarrollo de las directrices de ordenación del territorio y que se refieran a la zona geográfica propia de la comarca respectiva. También participarán en la elaboración de los programas de ordenación y promoción de recursos agrarios de montaña y en la gestión de las obras de infraestructura y servicios públicos básicos que se incluyan en aquéllos.

\section{COMARCAS Y MANCOMUNIDADES DE MUNICIPIOS}

La Ley de Administración Local de Aragón reconoce a los municipios aragoneses el derecho de asociarse libremente con otros para la ejecución en común de obras y servicios determinados de su competencia y para la intervención coordinada en aquellos asuntos que promuevan el desarrollo económico y social de su ámbito. Esa facultad de mancomunarse puede ser ejercida por municipios de provincias distintas, o entre los que no exista continuidad territorial - salvo que sea requerida por la naturaleza del fin concreto de la mancomunidad- e incluso con municipios pertenecientes a otras Comunidades Autónomas - con respeto de los requisitos legales que a ese fin estén en vigor en ellas-, lo que, junto con la concreción y no generalidad de las funciones del ente, diferencia de manera clara las mancomunidades de las comarcas.

Fomentada, desde tiempo atrás, su constitución por el Gobierno de Aragón, y con el especial asesoramiento y apoyo de las diputaciones pro- 
vinciales, han llegado a existir más de noventa mancomunidades voluntarias, agrupando a cerca de setecientos municipios. Sin embargo, y a pesar de las mejoras que han supuesto para la prestación de determinados servicios en muchos de ellos, las mancomunidades han sido consideradas como un importante primer paso de un necesario proceso de agrupación municipal más ambicioso. Por eso, la propia Ley de Administración Local ideó la calificación de mancomunidades de interés comarcal, que podría ser otorgada por la Diputación General a solicitud de aquéllas en las que quedaran justificadas la importancia de los fines mancomunados, la capacidad de gestión y la adecuación de su ámbito territorial a la delimitación comarcal.

Tal calificación exige la previa elaboración de un programa de actuación, en el que podrá incluirse el compromiso de ejercicio de la iniciativa para la creación de la comarca y la asunción con carácter provisional de las funciones, servicios y medios que corresponderían como entidad comarcal, al objeto de facilitar su inmediato funcionamiento una vez aprobada la ley de creación de la comarca. Las mancomunidades de interés comarcal podrán asumir las funciones de Consejo Consultivo Comarcal, con participación en los programas y actuaciones que, promovidos por la Diputación General de Aragón o por las diputaciones provinciales, hayan de realizarse en su ámbito geográfico.

Los consejos consultivos comarcales podían constituirse - antes de que se generalizara la implantación de las comarcas como entes locales en todo Aragón— no sólo por iniciativa de alguna mancomunidad, sino también por la de los propìos municipios, en número no inferior a las dos terceras partes de los incluidos en una delimitación comarcal y que representasen al menos los dos tercios del censo electoral del correspondiente territorio. Formados por los alcaldes afectados $-\mathrm{o}$ personas en quienes delegasen-, su objeto era el de funcionar con carácter deliberante y consultivo, hasta la constitución de los órganos comarcales. (A falta de iniciativa, o por inviabilidad de la formulada, la Diputación General podía crear una entidad, con la participación de los municipios interesados, por medio de una sociedad o un consorcio de interés comarcal).

Creada una comarca, si en su territorio existe alguna mancomunidad cuyos fines coincidan con competencias que aquélla asuma efectivamente como consecuencia del proceso de transferencias, ello determinará la conversión del servicio mancomunado en comarcal y la transferencia de su gestión al ente comarcal. Si tal servicio constituye el único fin de la mancomunidad, o si se produce la atribución a la comarca de competencias relacionadas con la totalidad de sus fines —en idéntico ámbito territo- 
rial一, el ente asociativo preexistente quedará extinguido; pero la subrogación en la gestión por parte de la comarca no comportará alteración del régimen estatutario del servicio respecto de los usuarios ni, en su caso, del concesionario. Los fondos que correspondan a las mancomunidades extintas se destinarán a financiar inversiones de carácter supramunicipal.

La comarca sucede, así, a la mancomunidad en cuanto sujeto público titular de las funciones mancomunadas. Se procederá, por lo tanto, al traspaso por las mancomunidades a las comarcas de las funciones y servicios afectados, así como de los medios adscritos a su gestión, comprendiendo entre ellos las transferencias para gastos corrientes e inversiones concedidas por el Gobierno de Aragón y por cualquier otra Administración Pública para financiar los servicios mancomunados. Si esta operación no se ejecutara en el plazo máximo que se fije en el decreto de transferencias, el incumplimiento determinaría el cese de cualquier subvención o ayuda de la Comunidad Autónoma a la mancomunidad.

La comarca y la mancomunidad deberán actuar de tal forma que a la disolución y liquidación de ésta, por conclusión de su objeto, quede garantizada la continuidad en la prestación de los servicios por parte de la comarca.

Cuando una mancomunidad esté compuesta por municipios pertenecientes a más de una delimitación comarcal, todos ellos en conjunto deberán concretar cuáles de los fines de la mancomunidad pueden ser asumidos por una o más de las comarcas afectadas, así como las repercusiones de ello sobre la mancomunidad, que, en su caso, habrá de proceder a modificar sus estatutos para adaptarlos a la nueva situación. Si su continuidad resultara inviable, aconsejando la disolución de la mancomunidad, la comarca que asuma sus fines podrá formalizar convenios con los municipios de otras comarcas limítrofes que lo requieran, para asegurar en ellos, hasta la constitución de la correspondiente comarca, el cumplimiento de los fines de la mancomunidad extinguida.

Una vez creada por Ley de Cortes de Aragón una comarca, no podrá constituirse en su territorio ninguna mancomunidad de ámbito general o comarcal.

\section{GESTIÓN}

A petición de los entes comarcales, la Diputación General de Aragón les prestará asesoramiento técnico en todos aquellos aspectos encaminados a 
garantizar la transición al nuevo marco competencial, y especialmente en materia de tramitación, gestión e informatización de los procedimientos administrativos. Pero, además, en tanto las comarcas no cuenten con personal propio, las funciones de naturaleza técnica atribuidas a Cuerpos o Escalas para cuyo ingreso se precise titulación de grado superior o medio y que sean necesarias para el ejercicio de determinadas competencias (gestión de montes, control sanitario de explotaciones ganaderas y del movimiento pecuario intracomarcal, sanidad y salubridad públicas, espacios naturales protegidos, actividades molestas, insalubres, nocivas y peligrosas, control sanitario de certámenes ganaderos, transporte por cable y, en general, funciones de custodia, policía y conservación de espacios naturales) seguirán siendo desempeñadas por el personal de la Administración de la Comunidad Autónoma que lo viniera realizando, mediante convenios en que se formalice la encomienda de gestión, cuyas bases habrán de contenerse en los decretos de transferencias de funciones y servicios.

Pero es que, también a través de la misma figura de encomienda de la gestión ordinaria de determinados servicios, el Consejo Comarcal podrá asignar a uno o varios municipios — previa aceptación de éstos- la realización de funciones ejecutivas correspondientes a competencias de la comarca, si ello supone mejora de la prestación.

Cuando la transferencia de alguna competencia a la comarca se refiera al fomento y promoción de actividades, ello incluirá la convocatoria de subvenciones y ayudas al sector privado, con cargo al presupuesto comarcal. Sin embargo, cuando, por el carácter de la actividad a subvencionar, en relación con los intereses generales de la Comunidad Autónoma, o por la necesidad de gestión centralizada o derivada de la normativa de la Unión Europea, no baste con la actividad que libremente lleven a cabo las comarcas, la Administración autonómica podrá convocar subvenciones y ayudas en el ámbito competencial transferido; en tales supuestos, podrán ambas entidades colaborar, mediante convenio, en las labores de difusión de las convocatorias, tramitación e informe de las solicitudes que se presenten.

En atención a los principios de eficacia en la gestión y de proximidad al ciudadano, los decretos de transferencias de funciones y servicios podrán contener la atribución competencial a las comarcas de la gestión de procedimientos administrativos, incluida la resolución final, siempre que se refieran a cualquiera de las materias incluidas en el listado legal de materias propias de las comarcas.

Y con respecto al ejercicio de la potestad sancionadora, en concreto, se especifica que, cuando sea anejo a alguna de las competencias transferi- 
das, el órgano competente para iniciar y resolver el procedimiento sancionatorio - y, por lo tanto, para sancionar- es el Presidente de la comarca, si bien la comarca puede, en uso de su potestad reglamentaria, atribuir tal competencia a órgano distinto - mientras no vulnere con ello lo establecido en la legislación sectorial—, como también complementar y adaptar el sistema de infracciones y sanciones establecido por las leyes sectoriales para introducir las especificaciones y graduaciones convenientes, siempre que no supongan infracciones ni sanciones nuevas ni alteren su naturaleza ni los límites cuantitativos fijados para las multas en la legislación sectorial aplicable, según la tipificación de las faltas como leves, graves y muy graves. La instrucción, tramitación y resolución de los expedientes se regirán por regulado en el Reglamento para el ejercicio de la potestad sancionadora de la Comunidad Autónoma, aprobado por Decreto 28/2001, de 30 de enero, del Gobierno de Aragón.

\section{PERSONAL}

La puesta en marcha y funcionamiento de los entes comarcales requiere, naturalmente, una cierta infraestructura burocrática — que se pretende escueta, ágil y funcional, evitando sobredimensionamientos antieconómicos-, la cual ha de someterse a los principios constitucionales y preceptos legales básicos en materia de función pública, dado que se trata, en definitiva, de Administraciones Públicas. Por lo tanto, se da una remisión expresa a lo dispuesto con carácter general en el Título VII de la Ley Reguladora de las Bases de Régimen Local.

Se entienden como funciones públicas necesarias en todas las comarcas la de Secretaría (comprensiva de la fe pública y el asesoramiento legal preceptivo) y la de control y fiscalización interna de la gestión económica y presupuestaria, así como las de contabilidad, tesorería y recaudación. La responsabilidad de estas funciones queda reservada a los funcionarios con habilitación de carácter nacional, y sus puestos de trabajo serán clasificados por la Administración de la Comunidad Autónoma atendiendo a criterios de población comarcal y del municipio capital, competencias de la comarca y presupuesto a gestionar.

Con el asesoramiento, si lo desea, de la Administración autonómica, cada comarca deberá formar y aprobar la relación de puestos de trabajo de su propio aparato administrativo, según lo indicado en la Ley de Administración Local de Aragón, la cual, a su vez, se remite a la legislaciones básica y autonómica sobre funcionarios. 
En esas relaciones podrán preverse puestos susceptibles de ser ocupados por funcionarios de otras comarcas. Además, la comarca y la Administración de la Comunidad Autónoma, de forma coordinada con la aprobación de la relación de puestos de trabajo de la primera, pueden suscribir un convenio en el que, para facilitar la aplicación de la movilidad, se determinen las equivalencias entre los cuerpos, escalas y especialidades funcionariales y los niveles, grupos y categorías del personal laboral de ambas Administraciones, lo que parece apuntar a una posibilidad de movilidad voluntaria no sólo intercomarcal sino también entre las comarcas y la Administración autonómica, que habrá de suponerse en ambas direcciones y no sólo en la de acceso a ésta desde las entidades locales - según lo previsto en el artículo 17.2 de la Ley de Medidas para la Reforma de la Función Pública-, para lo que en todo caso regirían las disposiciones de la Ley de Ordenación de la Función Pública de la Comunidad Autónoma de Aragón.

En el sentido opuesto, la modalidad más normal de traslado de personal de la Administración de la Comunidad Autónoma a las comarcas debería ser la transferencia, con ocasión de los decretos de traspasos de funciones y servicios que apruebe el Gobierno de Aragón. Este personal así transferido quedará en la citada Administración en la situación administrativa de servicios en otras Administraciones Públicas, de efectos similares a la situación administrativa especial prevista en el artículo 12 de la Ley 30/1984 - por lo que habrá de entenderse que se integran plenamente, en servicio activo, en la Administración de la comarca correspondiente-, conservando el derecho a reintegrarse al servicio activo en aquélla por los procedimientos pertinentes. Al personal transferido a las comarcas se les respetarán, a todos los efectos, el Grupo del Cuerpo y Escala de procedencia y los derechos inherentes al grado personal que tengan reconocido, hasta el correspondiente al nivel máximo del intervalo atribuido a su Grupo en la Administración comarcal. Y, además, se le garantiza el derecho - que debe quedar respetado en las relaciones de puestos de trabajoa la movilidad entre las diferentes comarcas, para acceder al desempeño de puestos de contenido funcional adecuado a su pertenencia corporativa y su especialización.

Sin embargo, la transferencia de personal autonómico a las comarcas no parece fácil en la práctica, por la escasa disponibilidad de voluntarios y lo conflictivo de los traslados forzosos. De hecho, ninguno de los decretos de transferencias aprobados hasta ahora incluye listados de personal. El propio legislador no debía de confiar mucho en aquella posibilidad, por cuanto prevé la creación de un Fondo para Gastos de Personal, destinado a 
financiar la estructura de personal necesaria para el ejercicio por las comarcas de las competencias transferidas por la Comunidad Autónoma, que se nutrirá con las dotaciones de personal amortizadas en los Departamentos y Organismos Autónomos del Gobierno de Aragón y que deberá actualizarse por aplicación de los porcentajes de aumento salarial anual que figuren en las sucesivas leyes de Presupuestos Generales de la Comunidad Autónoma. A medida que las comarcas vayan recibiendo efectivamente las transferencias, se traspasarán las cuantías necesarias desde ese Fondo a las partidas presupuestarias que recojan las transferencias incondicionadas para cada comarca. Mientras no se completen los traspasos de funciones a todas ellas, los servicios de contabilidad de la Diputación General de Aragón realizarán de oficio retenciones de crédito sobre las dotaciones de todos los puestos de trabajo de la Administración autonómica que estén o queden en el futuro vacantes, excepto los de funciones docentes o sanitarias; dichas retenciones sólo podrán ser levantadas, para cada caso, por orden conjunta de los Consejeros competentes en Política Territorial y en Hacienda, a propuesta del titular del Departamento afectado, y se considerará nula de pleno derecho la provisión, por cualquier forma, de un puesto cuya retención no haya sido así levantada. Hasta el final del proceso de transferencias, las leyes de presupuestos de la Comunidad Autónoma incluirán en los anexos de personal la relación con el detalle de las plazas que previsiblemente se amortizarán durante el ejercicio presupuestario.

Por lo demás — cuenten o no con personal transferido- las comarcas deberán formular con carácter anual sus respectivas ofertas de empleo público, en cumplimiento de las cuales seleccionarán su personal propio, tanto funcionario como laboral, mediante convocatoria pública y a través de los sistemas de concurso, oposición o concurso-oposición libres, en los que se garanticen, en todo caso, los principios constitucionales de igualdad, mérito y capacidad, así como el de publicidad. Dado que se transcribe literalmente el precepto considerado base y recogido también en la Ley autonómica de Función Pública, es obligado considerar que, al ejecutar los procesos selectivos derivados de la oferta de empleo público, la comarca está sujeta a las normas de desarrollo que en ambas legislaciones, así como en la de Régimen Local, rigen para las Administraciones Públicas.

\section{FINANCIACIÓN}

Los recursos que constituyen la Hacienda de la comarca son: 
- Ingresos procedentes de su patrimonio y demás de Derecho privado

- Tasas por la prestación de servicios o realización de actividades de su competencia

— Los percibidos en concepto de precios públicos

- Contribuciones especiales

- Subvenciones

- Transferencias de la Comunidad Autónoma y de la provincia, en concepto de:

- Participación en sus ingresos sin carácter finalista

- Traspaso de medios en virtud de redistribución legal

- Transferencia o delegación de competencias

- Aportaciones de los municipios que la integran

- Los procedentes de operaciones de crédito

- El producto de las multas y sanciones impuestas en uso de sus competencias

- Cualesquiera otras que resulten establecidas por ley.

Las leyes de Presupuestos de la Comunidad Autónoma establecerán anualmente las transferencias incondicionadas de créditos a favor de las comarcas, para la puesta en marcha y funcionamiento de su organización y actividades, y deberán contener asimismo un estado territorializado por comarcas de las inversiones y transferencias de capital que se les destinen, como visión conjunta de los distintos programas departamentales. Cada año deberá la Diputación General elevar a las Cortes de Aragón un informe sobre el proceso de asunción de competencias por las comarcas, grado de cumplimiento y correlativa asignación de recursos económicos.

El Fondo para Gastos de Personal, antes citado, así como un Fondo de Cohesión Comarcal — destinado a corregir, mediante asignaciones de carácter finalista, en tanto se culminan los procesos de traspasos, los desequilibrios y desajustes que se produzcan, y dotado con parte de las cantidades detraídas de los programas de gastos de los Departamentos y Organismos del Gobierno de Aragón para financiar el coste de las transferencias - se incluyen en una específica sección de los Presupuestos de la Comunidad Autónoma, donde se ubicarán los créditos destinados a financiar los traspasos de funciones y servicios a las comarcas constituidas. Los créditos de esta sección son gestionados conjuntamente por los Consejeros competentes en materia de Política Territorial y de Hacienda, y los gas- 
tos con cargo a aquéllos se realizarán, con carácter general, mediante transferencias incondicionadas y de abono anticipado trimestralmente a las comarcas - salvo lo que se disponga en la legislación sectorial o en los decretos de traspasos.

La valoración del coste del traspaso de funciones y servicios asociados a las competencias que pueden transferirse a las comarcas se fija, para cada programa de gasto, en las cantidades que figuran en el anexo de la Ley de Medidas de Comarcalización, con referencia al año 2002, y deberán actualizarse en los sucesivos ejercicios según los que dispongan las leyes de Presupuestos de la Comunidad Autónoma. A tales cantidades, a excepción de las dotaciones de personal y una vez deducido lo consignado en el Fondo de Cohesión Territorial, se les aplica una fórmula de reparto comarcal de acuerdo con las reglas siguientes: una cantidad fija resultante de distribuir el $40 \%$ por partes iguales entre todas las delimitaciones comarcales; del $60 \%$ restante, un $25 \%$ se distribuirá en proporción al número de municipios y núcleos de población diferenciados existentes en cada comarca, y el otro $75 \%$ en proporción al número de habitantes de derecho de los municipios de la delimitación comarcal. Las comarcas recibirán las cuantías resultantes de la aplicación de tales reglas para cada competencia que tengan traspasada (en los primeros quince días del ejercicio las correspondientes a gastos de puesta en marcha y funcionamiento, y en la primera quincena de cada trimestre las que compensen el coste de las funciones y servicios).

Por otra parte, las comarcas que tengan constituido su consejo comarcal recibirán, también de forma anticipada e incondicional, las cuantías del Programa de Política Territorial — previsto en la Ley de Administración Local de Aragón- que estén destinadas a la financiación de inversiones de carácter supramunicipal en el respectivo territorio, así como las necesarias para la puesta en marcha y funcionamiento de la organización y actividades de las comarcas constituidas, de acuerdo con una escala que agrupa a las comarcas con menos de diez mil habitantes, las que tienen entre diez mil uno y veinticinco mil, las de veinticinco mil uno hasta cincuenta mil y las que cuentan con población superior a esta última cantidad.

Cuando la comarca asuma la ejecución de obras y prestación de servicios a los municipios de su ámbito, que tengan el carácter legal de mínimos y obligatorios, o de funciones públicas necesarias, si no se hubiera resuelto se realización por la provincia, ésta deberá colaborar económicamente en su financiación, en la proporción que se convenga. En los presupuestos provinciales podrán preverse transferencias incondicionadas a las 
comarcas en atención al conjunto de servicios de cooperación y asistencia a los municipios que presten subsidiariamente.

En cuanto a las aportaciones de los municipios a las comarcas, se determinarán en función de su número de habitantes y del aprovechamiento de los servicios prestados por la respectiva comarca; el Consejo Comarcal revisará cada año, al aprobar el Presupuesto, los criterios para fijar dichas aportaciones.

Se ajustará a lo establecido en la legislación sobre haciendas locales el régimen presupuestario de intervención y contabilidad de las comarcas.

\section{MEDIDAS COMPLEMENTARIAS}

Por claras razones de congruencia, el desarrollo del proceso comarcalizador debe ir acompañado de determinados cambios en la organización de la propia Administración de la Comunidad Autónoma, que afectan sobre todo a su estructura periférica. Así, la Ley de Comarcalización otorga a la Diputación General —en la disposición adicional primera - un plazo de seis meses para unificar las divisiones comarcales y supramunicipales que vinieran aplicándose por los diferentes Departamentos en la organización y gestión de los servicios a su cargo, con el fin de procurar la homogeneización del mapa comarcal como base geográfica de los servicios periféricos, de tal modo que éstos se refieran siempre a un área comarcal o a un conjunto de áreas comarcales determinadas.

También en disposición adicional, la Ley de Delimitación Comarcal ordena a todos los Departamentos llevar a cabo el necesario proceso de adaptación de sus respectivos servicios periféricos para utilizar en adelante, como base territorial para éstos, las divisiones recogidas en la Ley; y que cuando, excepcionalmente, en un sector concreto de la acción pública deban atenderse áreas de menor extensión, el conjunto de dos o más subcomarcas coincida con alguna de las áreas comarcales delimitadas.

En coherencia con lo anterior, la Ley de la Administración de la Comunidad Autónoma de Aragón - cuyo Texto Refundido fue aprobado por Decreto Legislativo 2/2001, de 3 de julio-, al referirse a la división funcional y gestión territorial (art. 7), prevé la posibilidad de crear otros órganos o unidades administrativas de ámbito provincial, supracomarcal, comarcal o local. El establecimiento, mediante Decreto del Gobierno de Aragón, de la organización territorial de la Administración de la Comunidad Autónoma habrá de hacerse de conformidad, en su caso, con lo pre- 
visto en la Ley de Comarcalización de Aragón (art. 22) y, en relación con ello, a propuesta del Consejero de Presidencia y Relaciones Institucionales, podrán crearse Oficinas Delegadas de carácter interdepartamental, que comprenderán una o varias delimitaciones comarcales, según las características geográficas, demográficas o sociales de éstas.

Según el Decreto 74/2000, de 11 de abril, de Reorganización de la Administración Periférica de la Administración de la Comunidad Autónoma de Aragón, el Gobierno, con el fin de racionalizar y agilizar la prestación de servicios mediante su adecuada desconcentración, establecerá una red de Oficinas Delegadas de carácter interdepartamental en las cabeceras supracomarcales y en aquellas comarcas o localidades en las que el volumen de los servicios prestados por la Administración autonómica, o bien las características geográficas, demográficas o sociales, lo aconsejen. Tales Oficinas Delegadas se adscriben orgánicamente a las Delegaciones Territoriales del Gobierno de Aragón en Huesca y Teruel y, en el caso de las de la provincia de Zaragoza, a la Secretaría General Técnica del .Departamento de Presidencia y Relaciones Institucionales. Por Orden conjunta de los Consejeros titular del citado Departamento y de Economía, Hacienda y Empleo, serán aprobadas las Relaciones de Puestos de Trabajo de cada una de las Oficinas Delegadas, cuya respectiva estructura orgánica quedará así establecida. Dada su naturaleza de órganos administrativos de carácter interdepartamental, a ellas se adscriben todas las unidades, servicios y dependencias administrativas existentes en el correspondiente ámbito territorial, para que lleven a cabo su actuación bajo el principio de unidad de dirección, sin perjuicio de la dependencia funcional de los Departamentos cuyas competencias gestionen y bajo cuyas directrices realizarán su actividad. Han sido puestas en funcionamiento, hasta ahora, las Oficinas Delegadas de Jaca (en la provincia de Huesca), Calatayud, Ejea de los Caballeros y Tarazona (en la provincia de Zaragoza), Alcañiz y Calamocha (en la provincia de Teruel), y se proyecta el establecimiento de algunas otras, hasta completar una verdadera Red de Oficinas Delegadas.

Finalmente, el Pleno de las Cortes de Aragón, en sesión celebrada el día 28 de junio de 2001, con motivo del debate de una comunicación remitida por la Diputación General, aprobó, a propuesta conjunta de todos los Grupos Parlamentarios, un conjunto de resoluciones en las que se explicitan las medidas a incluir en un Plan de reorganización de la Administración de la Comunidad Autónoma de Aragón ante el proceso de comarcalización, que el Gobierno aragonés debe elaborar, con los siguientes objetivos:

- Cohesión socioterritorial de la Comunidad Autónoma de Aragón 
- Definición territorial de la planta administrativa de la organización periférica

- Desconcentración administrativa en los órganos periféricos de la Administración autonómica

- Descentralización administrativa en las comarcas

- Mejora de la calidad de los servicios poúblicos

- Reordenación de los recursos humanos y presupuestarios de forma que este proceso no suponga costes adicionales (el denominado coste cero).

\section{CONSIDERACIÓN FINAL}

Con la salvedad del área geográfica correspondiente a una posible entidad metropolitana de Zaragoza, el territorio aragonés ha quedado comarcalizado, en un proceso de inusitada rapidez, incluso crecientemente acelerado, puesto que en poco más de dos años se habrán creado, constituido y puesto en funcionamiento las treinta y dos comarcas restantes, con la aquiescencia prácticamente unánime de las fuerzas políticas de la Comunidad Autónoma. Pero éste no es el final, sino más bien el comienzo del camino. A partir de aquí, habrá que observar la viabilidad real del proyecto, valorar — sin agobios - los resultados de la experiencia, comprobar que las nuevas entidades están suficientemente capacitadas para la gestión de las funciones que ya les competen, acercando de verdad la Administración a los ciudadanos, mejorando los niveles de eficacia, economía y calidad de los servicios públicos y actuando con la agilidad incompatible con un aparato burocrático sobredimensionado. Una organización escueta y eficiente dedicada a aumentar los niveles de bienestar de los habitantes de las zonas rurales y revitalizar los núcleos de población más alejados de las condiciones de vida de nuestro tiempo.

Se trata de demostrar que la creación de un nivel administrativo más no supone superposición con respecto a los preexistentes, sino perfeccionamiento del conjunto. Aquí, en las relaciones de las comarcas con las otras Administraciones actuantes en su ámbito territorial, se suscitan algunas dudas de futuro, que me limito a exponer. ¿En qué medida afectarían al sistema comarcal construido los nuevos modos de organización y gestión municipales que se barajan formando parte de una hipotética reforma de la Ley de Bases de Régimen Local? ¿Cuál será, en un horizonte de medio plazo, el papel de las diputaciones provinciales, ante el avance de las com- 
petencias de las comarcas y la previsible prestación por éstas a los municipios de algunos de los servicios tradicionales de aquéllas? ¿Cómo han de plantearse las funciones de los órganos de la Administración periférica de la Comunidad Autónoma, y muy señaladamente las de las Oficinas Delegadas del Gobierno de Aragón, en una probable situación de cuasi vaciamiento competencial en favor de las comarcas?...

A estos interrogantes, que tienen que ver sobre todo con la dimensión administrativa de las comarcas, con su misión prestacional y garantizadora de los servicios públicos locales, se añade otro, referido a la dimensión política de las nuevas entidades. ¿Cuál va a ser, en definitiva, su significado, en el contexto de las instituciones representativas en el que se insertan? Según informaciones públicas, el Gobierno de Aragón estudia una posible reforma de la Ley Electoral de la Comunidad Autónoma que, manteniendo en parte el actual sistema proporcional, permitiese a la vez la elección directa de diputados comarcales a las Cortes de Aragón, introduciendo, así, un modelo mixto que potenciaría la identidad política de la comarca. La citada Ley Electoral atribuye un mínimo de trece diputados a cada una de las tres provincias aragonesas, mientras que el resto, hasta el total de sesenta y siete, se distribuye proporcionalmente a la población de cada una de ellas; la reforma consistiría en que treinta y cuatro diputados seguirían siendo elegidos como hasta ahora, en listas cerradas confeccionadas por los partidos por provincias, y los treinta y tres restantes serían elegidos uno en cada comarca, en listas abiertas, mediante sufragio directo, lo que implicaría una más personalizada participación de los ciudadanos en su condición de vecinos de las comarcas. Claro que ello requeriría también una modificación estatutaria que permitiera que, a tal efecto, la circunscripción electoral sea, no la provincia, como fija el artículo 18.4 del Estatuto de Autonomía, sino la comarca. Lo cual resultaría congruente con la previsión del artículo 5 del propio Estatuto, que ha dado pie a poner en marcha la comarcalización de Aragón.

\section{SELECCIÓN DE BIBLIOGRAFÍA}

BIELZA DE ORY, V,, Bases y propuestas para la comarcalización de Aragón, D.G.A., Zaragoza, 1992.

EMBID IRUjo, A., «La comarcalización: un cambio trascendental en la organización territorial de la Comunidad Autónoma de Aragón», Revista Aragonesa de Administración Pública (RArAP) nº 20 (2002), pgs. 83 y ss. 
FERREIRA FERnández, A.J., El régimen jurídico de la comarca en el sistema autonómico español, Cedecs, Barcelona, 1999.

Fanlo Loras, A., «La Administración Local», en Derecho Público Aragonés, dir. por A.Embid Irujo, Dykinson, Madrid, 2000.

— «Competencias de las comarcas», en La comarcalización de Aragón, dir. por R.Salanova Alcalde, Cortes de Aragón, Zaragoza, 2002.

JiMÉNEZ COMPAIRED, I., «La Hacienda comarcal»,en La comarcalización de Aragón, dir. por R.Salanova Alcalde, Cortes de Aragón, Zaragoza, 2002.

Martínez Pallarés, P.L., «El régimen local aragonés», en Derecho de las Instituciones públicas aragonesas (libro dedicado a Manuel Giménez Abad), Justicia de Aragón e Ibercaja, Zaragoza, 2002.

Oliván del Cacho, J., y Tena Piazuelo, V., «Los Consejos Comarcales: aspectos organizativos y régimen de su personal», en La comarcalización de Aragón, dir. por R.Salanova Alcalde, Cortes de Aragón, Zaragoza, 2002.

- Propuestas para una política territorial de Aragón (comunicación y resoluciones de las Cortes de Aragón), D.G.A., Zaragoza, 1992.

Rodríguez-Arana Muñoz, J., y Raposo Arceo, J., «Notas sobre la funcionalidad de la comarca», RarAP no 3 (1993), pgs. 335 y ss.

Revista TERRITORIO, del Dpto. de Presidencia y Relaciones Institucionales del Gobierno de Aragón, n ${ }^{\circ}$, marzo-abril 2003.

Salanova Alcalde, R., «La Administración Local en Aragón», RarAP n ${ }^{\circ}$ 1 (1992),pgs 159 y ss

- Mancomunidades de municipios y autonomía municipal, D.G.A., Zaragoza, 1993 (2 $2^{\text {a }}$ ed.)

- «La comarca en Aragón. La Ley 10/93, de 4 de noviembre», RarAP $\mathrm{n}^{\circ} 4$ (1994), pgs 293 y ss.

- «La construcción de un modelo propio de organización territorial de Aragón», en Derecho de las Instituciones Públicas aragonesas (libro dedicado a Manuel Jiménez Abad), Justicia de Aragón e Ibercaja, Zaragoza, 2002. 
— «El modelo aragonés de comarca. La creación de las comarcas. El proceso de comarcalización» y «La delimitación comarcal», en La comarcalización de Aragón, dir. por R.S.A., Cortes de Aragón, Zaragoza, 2002.

Ubieto ARtetA, A., El largo camino hacia las comarcas de Aragón, D.G.A., 2001. 